\title{
Biosurfactant as an Environmental Remediation Agent: Toxicity, Formulation, and Application in the Removal of Petroderivate in Sand and Rock Walls
}

\author{
Italo Durval ${ }^{1,4}(\mathbb{D})$, Raquel Rufino ${ }^{2,4}(\mathbb{D})$, Leonie Sarubbo ${ }^{3,4 *(\mathbb{D})}$ \\ 1 Northeast Biotechnology Network (RENORBIO), Federal Rural University of Pernambuco, Recife, Pernambuco, Brazil; \\ italo.durval@gmail.com (I.D.); \\ 2 Center for Biological and Health Sciences, Catholic University of Pernambuco, Recife, Pernambuco, Brazil; \\ raqueldrufino@yahoo.com.br (R.R.); \\ 3 Science and Technology Center, Catholic University of Pernambuco, Recife, Pernambuco, Brazil.; \\ leonie.sarubbo@unicap.br (L.S.); \\ 4 Advanced Institute of Technology and Innovation (IATI), Recife, Pernambuco, Brazil \\ * Correspondence: leonie.sarubbo@unicap.br;
}

Received: 13.04 2021; Revised: 6.04.2021; Accepted: 9.04.2021; Published: 19.042021

\begin{abstract}
The exploitation and transportation of petroleum products are important reasons for environmental concern since they are the major causes of accidents involving oil spills. Therefore, the biosurfactant produced by the bacterium Bacillus cereus UCP1615 was applied in the removal of motor oil from sand and stones from coastal regions. Bioassays carried out with the microcrustacean Artemia salina and three vegetables' seeds showed that the biosurfactant has reduced toxicity. The application of the biosurfactant in crude and isolated form, as a removal agent, was carried out in static and kinetic tests using sand contaminated with motor oil, in packed columns, and in flasks under orbital agitation, respectively. The results showed that the biosurfactant removed $63.0 \pm 2.1 \%$ of the hydrocarbon in the static test and $84.0 \pm 2.2 \%$ in the dynamic test. In tests using rock wall samples, the removal rates reached $69.0 \pm 2.0 \%$. Conservation tests carried out during 120 days demonstrated that the surfactant activities were maintained, especially in the presence of the preservative potassium sorbate. The B. cereus biosurfactant has proven to be a biocompatible, effective, and stable alternative for applications in environments contaminated with hydrophobic compounds and can be industrially stored for application in the event of possible environmental disasters.
\end{abstract}

Keywords: bioremediation; petroderivates; biosurfactant.

(C) 2021 by the authors. This article is an open-access article distributed under the terms and conditions of the Creative Commons Attribution (CC BY) license (https://creativecommons.org/licenses/by/4.0/).

\section{Introduction}

Technological advances in containing disasters involving petroleum products have not ended up with the risk of leaks. In 2018, more than 110 thousand tons of oil were spilled in marine waters throughout the world [1]. Unfortunately, oil spills are recurring events with great environmental impacts in short to long term due to the recalcitrance of some of the oils' components [2].

One of the greatest examples in history occurred at the end of August 2019, when spots of crude oil of unknown origin began to appear on the Brazilian coast, mainly in the Northeast region. About 3,000 km of coastline were affected, with more than 200 tons of oily material removed in the first five months [1,3]. Among the various socioeconomic impacts, it is 
necessary to highlight the prohibition of fishing, affecting traditional communities, and tourism, since the beaches were banned for leisure due to oil contamination [4].

Surfactants arise as a mitigating technology for oil spills as these compounds have amphipathic structures that tend to be distributed at the interfaces between fluid phases with different degrees of polarity, promoting the reduction of surface and interfacial tension. They have been included in dispersant formulations used in oil spills. This compound class has a diverse and significant role in several market segments, including the oil, soap, and detergent industry, and even in the food, pharmaceutical, and cosmetics industries [5]. Biosurfactants, in turn, appear as an alternative to chemical surfactants, being derived from microorganisms and presenting the same efficiency and great diversity in terms of function and structure [6].

Biosurfactants, in turn, appear as an alternative to chemical surfactants. These biomolecules are mainly produced by microorganisms and show the same efficiency and great diversity in terms of structure and function when compared to their chemical counterparts [6]. Biosurfactants have several advantages over chemical surfactants. They can be produced from renewable sources, are biodegradable, have activity under a wide range of environmental conditions, and reduce toxicity [7]. Biosurfactants can assist in the recovery of contaminated soils and/or removal of hydrophobic compounds [8] and heavy metals [9], in addition to being able to assist in livestock [10] and agriculture as an alternative to pesticides [11] or increasing the wettability and uniform distribution of fertilizers in the soil [12].

Bacillus species are cosmopolitan and morphologically diverse. Industrial interest in this genus has grown due to several species' ability to synthesize and secrete five cyclic lipopeptide groups. Surfactin is the most relevant lipopeptide produced, followed by iturin and phengicin [13]. Lipopeptides stand out in the literature for their versatility, which makes them potentially useful in the industry. Research has highlighted the use of these compounds in bioremediation [11], as bioemulsifiers [14], and antibiotic, antifungal and antitumor agents [15].

Thus, this work evaluated the biosurfactant from Bacillus cereus UCP1615, verifying its toxicity against an organism considered an environmental bioindicator and vegetable seeds, with a view of its environmental application oil removal processes in the coastal region. In addition, the conservation of the biomolecule's tensio-active properties in the long term was evaluated, using a possible formulation with potassium sorbate to propose a commercial product as an environmental remediation agent.

\section{Materials and Methods}

\subsection{Materials.}

All chemicals were of reagent grade. Motor oil was used as contaminant oil that is commercially available for use in flex engines (gasoline, VNG, and alcohol), type SAE 20W50, with synthetic guard (PETROBRAS, Brazil). It consists of a paraffinic base lubricating oil (a complex mixture of hydrocarbons) and performance-enhancing additives. The oil's viscosity is $98.0 \mathrm{cSt}$ (at $40^{\circ} \mathrm{C}$ ), and its density is $0.9420 \mathrm{~g} / \mathrm{mL}$ (at $20^{\circ} \mathrm{C}$ ). The frying soybean oil was obtained in the industry ASA S.A., PE, Brazil.

\subsection{Microorganism.}

The bacterium Bacillus cereus UCP 1615, deposited in the Culture Bank of the Catholic University of Pernambuco, was used as the biosurfactant producer. 


\subsection{Production and isolation of biosurfactant.}

The conditions of the biosurfactant's production and isolation followed the methods described by Durval et al. (2020), using a mineral medium supplemented with $2 \%$ residual frying soybean oil and $0.12 \%$ peptone with the $\mathrm{pH}$ adjusted to $7.0 \pm 0.2$. The surface tension of the culture medium before inoculation was measured as $57 \mathrm{mN} / \mathrm{m}$. Fermentations were carried out under $250 \mathrm{rpm}$ agitation for $48 \mathrm{~h}$, at $28{ }^{\circ} \mathrm{C}$. The biosurfactant was extracted after centrifugation of the fermentation broth at $5000 \times \mathrm{g}$ for $30 \mathrm{~min}$ to remove cells. A solution of $6.0 \mathrm{M} \mathrm{HCl}$ was added to the supernatant to adjust the $\mathrm{pH}$ to 2.0 , followed by the addition of a 2:1 (v/v) $\mathrm{CHCl}_{3} / \mathrm{CH}_{3} \mathrm{OH}$ solution. After vigorous manual agitation during $15 \mathrm{~min}$ and phase separation, the organic phase was removed, and the operation was repeated twice more. The organic phases were pooled, and the isolated biosurfactant was concentrated in a rotary evaporator.

\subsection{Surface tension and critical micelle concentration (CMC) determination.}

Surface tension was measured in cell-free metabolic broth (crude biosurfactant) using a Sigma 700 tensiometer (KSV Instruments, Helsinki, Finland) and Du Nuöy ring. The average reduction of the surface tension in the presence of the biosurfactant from Bacillus cereus UCP 1615 was reported as $27 \mathrm{mN} / \mathrm{m}$. The critical micelle concentration (CMC) of the isolated biosurfactant was determined automatically in the tensiometer. The CMC was previously determined and expressed as $0.5 \mathrm{~g} / \mathrm{L}$ [16].

\subsection{Determination of biosurfactant toxicity.}

The biosurfactant's toxicity was determined using brine shrimp and vegetable seeds, which were obtained in local stores.

The toxicity of the isolated biosurfactant was determined at concentrations of $0.25 \mathrm{~g} / \mathrm{L}$ (1/2 CMC), $0.5 \mathrm{~g} / \mathrm{L}$ (CMC) and $1 \mathrm{~g} / \mathrm{L}$ (2x CMC) using the microcrustacean Artemia salina as the bioindicator. The analyzes were carried out in penicillin tubes containing 10 larvae of the brine shrimp in $5 \mathrm{ml}$ of saline water $(33 \mathrm{mg} / \mathrm{L})$. The larvae were observed for 24 hours to determine the mortality rate. Saline water was used as a control, and the experiments were carried out in triplicate. Toxicity (concentration of biosurfactant per $100 \mathrm{ml}$ of saline water) was defined as the lowest concentration to kill all the brine shrimp [17].

The phytotoxicity of the biosurfactant was also evaluated in a static test involving the seed germination and root elongation of gherkin (Cucumis anguria), cabbage (Brassica oleracea), and tomato (Solanum lycopersicum) [18]. The cell-free metabolic broth (crude biosurfactant) and the isolated biosurfactant at concentrations of of $0.25 \mathrm{~g} / \mathrm{L}(1 / 2 \mathrm{CMC}), 0.5$ $\mathrm{g} / \mathrm{L}(\mathrm{CMC})$ and $1 \mathrm{~g} / \mathrm{L}(2 \mathrm{x} \mathrm{CMC}) 1 / 2$ were tested. Toxicity was determined in sterilized Petri dishes $(10 \mathrm{~cm})$ containing Whatman $\mathrm{N}^{\circ} 1$ filter paper. The vegetable seeds were previously treated with sodium hypochlorite. Ten seeds were inoculated in a Petri dish, followed by the addition of $5 \mathrm{ml}$ of the test solution at $27{ }^{\circ} \mathrm{C}$. After five days of incubation in the dark, root elongation ( $\geq 5 \mathrm{~mm}$ ), seed germination, and germination index (GI) were calculated as follows: Relative seed germination $(\%)=$ (number of seeds germinated in the extract/number of seeds germinated in control) $x 100$

Relative root length $(\%)=($ mean root length in the extract/mean root length in the control) $\mathrm{x}$ 100

$\mathrm{GI}=[(\%$ seed germination $) \times(\%$ root growth $)] / 100 \%$ 
Controls were prepared with distilled water to replace the biosurfactant solutions. Mean and standard deviation values of triplicate samples were calculated for each concentration.

\subsection{Removal of motor oil from packed columns through static assay.}

Glass columns measuring $55 \mathrm{~cm}$ in height $\mathrm{x} 6 \mathrm{~cm}$ in diameter were initially filled with approximately $200 \mathrm{~g}$ of a mixture containing the soils and $20 \mathrm{~g}$ of motor oil (15 cSt). The surface of the mixture was then inundated with $200 \mathrm{~mL}$ of the biosurfactant solutions. Isolated biosurfactant solutions at concentrations of $0.25 \mathrm{~g} / \mathrm{L}$ (1/2 CMC), $0.5 \mathrm{~g} / \mathrm{L}$ (CMC) and $1 \mathrm{~g} / \mathrm{L}(2 \mathrm{x}$ $\mathrm{CMC}$ ) in distilled water were prepared. Pure distilled water was used as the control. The cellfree broth, i.e., the crude biosurfactant, was also tested at the same volume. The percolation of the solutions was monitored for $24 \mathrm{~h}$ in 5-min intervals when no further percolation was observed. The soil samples in the columns were then washed with $20 \mathrm{~mL}$ of hexane to remove oil. The solvent was evaporated at $50{ }^{\circ} \mathrm{C}$, and the amount of oil removed was calculated by gravimetry [19].

\subsection{Removal of motor oil through kinetic assay.}

The removal of motor oil through the kinetic assay was determined after the saturation of $50 \mathrm{~g}$ of soil with $5 \mathrm{~g}$ of motor oil. The laboratory-contaminated soil was placed in $250-\mathrm{mL}$ Erlenmeyer flasks, to which $50 \mathrm{~mL}$ of the crude biosurfactant (cell-free metabolic broth) after fermentation and isolated biosurfactant at $1 / 2$ CMC $(0.25 \mathrm{~g} / \mathrm{L})$, at the CMC $(0.5 \mathrm{~g} / \mathrm{L})$ and twice the CMC $(1 \mathrm{~g} / \mathrm{L})$ were added. The flasks were maintained at $150 \mathrm{rpm}$ for $24 \mathrm{~h}$ at $28^{\circ} \mathrm{C}$. After this period, the flasks' content was centrifuged at $5000 \mathrm{rpm}$ for $1200 \mathrm{~s}$ and the residual oil in the supernatant, and the content of oil that remained in the soil was washed with hexane (50 $\mathrm{mL}$ ) three times. The solvent was roto-evaporated at $50{ }^{\circ} \mathrm{C}$, and the amount of oil in both samples was determined by gravimetry [20].

\subsection{Washing of hydrophobic compound adsorbed to the porous surface.}

The biosurfactant's capacity in removing motor oil adsorbed to rocks was carried out by soaking the samples of rocks in the oil until complete coverage and recording the oil volume spent. The material was then carefully placed in a $100-\mathrm{ml}$ beaker with the aid of pincers and submitted to washing with the cell-free metabolic broth (crude biosurfactant) and solutions of the isolated biosurfactant at $1 / 2 \mathrm{CMC}(0.25 \mathrm{~g} / \mathrm{L})$, at the CMC $(0.5 \mathrm{~g} / \mathrm{L})$, and at twice the CMC $(1 \mathrm{~g} / \mathrm{L})$. After the process, the oil removal was calculated by gravimetry from the amount of oil remaining on the biosurfactant-washed rock. [21].

\subsection{Conservation of biosurfactant properties evaluation for commercial formulation.}

The cell-free broth (crude biosurfactant) was subjected to three conservation methods: (a) addition of $0.2 \%$ potassium sorbate; (b) heating at $80{ }^{\circ} \mathrm{C}$ for $30 \mathrm{~min}$ (fluent vapor), followed by the addition of $0.2 \%$ potassium sorbate; and (c) sterilization at $121^{\circ} \mathrm{C}$ for $30 \mathrm{~min}$ for three consecutive days (fractionated tyndallization). After treatments, the crude biosurfactant was stored under different conditions, that is, at temperatures of 40 and $50^{\circ} \mathrm{C}$, under concentrations of 1, 3, and 5\% NaCl and at $\mathrm{pH} 5,7$, and 9 for 120 days. Samples were taken after 15, 30, 45, 90, and 120 days to determine stability. Measurements of surface tension, emulsification index, and the ability to disperse the seawater's oil were carried out to select the best conservation method [22]. 


\subsection{Emulsification activity with motor oil.}

The emulsification index was determined according to Cooper and Goldenberg [23], whereby equal volumes $(2 \mathrm{~mL})$ of motor oil and cell-free metabolic broth were added in a graduated screwcap tube and vortexed for $2 \mathrm{~min}$ at high speed. The emulsion's stability was determined after $24 \mathrm{~h}$, and the emulsification index was calculated by dividing the measured height of the emulsion layer by the total height of the mixture and multiplying by 100 .

\subsection{Motor oil displacement test (dispersant test).}

The oil displacement test was performed by slowly adding $20 \mu \mathrm{L}$ of motor oil to the seawater's surface $(40 \mathrm{~mL})$ contained in a $15 \mathrm{~cm}$ diameter Petri dish. Then, $10 \mu \mathrm{L}$ of the cellfree broth (crude biosurfactant) was added to the oil surface, causing clear zones to appear in the center of the oil. The clear zones' diameter was measured with a ruler, and the dispersion rate was calculated as a function of the Petri dish's diameter. The experiments were carried out in triplicate [24].

\subsection{Statistical analysis.}

Surface tension, stability, and emulsification were determined at least three times. Mean and standard error values were calculated using the Microsoft Office Excel 2003 (Version7). Tukey's test (P\0.05) was used to locate significant differences with the aid of software Statistica Version12.0.

\section{Results and Discussion}

\subsection{Results.}

\subsubsection{Evaluation of biosurfactant toxicity against Artemia salina.}

The biosurfactant produced by B. cereus UCP 1615 , at concentrations of $1 / 2 \mathrm{CMC}$, at the $\mathrm{CMC}$, and at twice the CMC, was not toxic to Artemia salina larvae exposed to these solutions for 24 hours, which showed a $100 \%$ survival rate.

\subsubsection{Evaluation of the toxicity of the biosurfactant against vegetable seeds.}

Seeds of gherkin seeds (Cucumis anguria), tomatoes (Solanum lycopersicum), and cabbage (Brassica oleracea) were exposed to the biosurfactant of Bacillus cereus, and the response of this bioassay resulted in germination indices (GI) shown in Table 1.

The present study showed results indicating that the biosurfactant solutions in different concentrations had no inhibitory effect on seed germination, highlighting the action against tomato seeds (Solanum lycopersicum), with GI above 100\%, exceeding the germination index of the control. In addition, leaf growth and elongation of secondary roots occurred under all conditions tested. It can be inferred that the biotensoactive has low toxicity, with the possibility of stimulating growth in concentrations close to or below its $\mathrm{CMC}(0.5 \mathrm{~g} / \mathrm{L})$ and being considered non-toxic. The use of crude biosurfactant (cell-free metabolic broth) resulted in the lowest germination rates of the studied vegetables. 
Table 1. Phytotoxicity evaluation of the biosurfactant from B. cereus 1615 against gherkin (Cucumis anguria), tomato (Solanum lycopersicum), and cabbage (Brassica oleracea) seeds.

\begin{tabular}{l|c|c|c}
\multirow{2}{*}{ Biosurfactant } & \multicolumn{3}{|c}{ Germination Index (\%) } \\
\cline { 2 - 4 } & Gherkin & Tomato & Cabbage \\
\hline $\begin{array}{l}\text { Crude (cell-free metabolic } \\
\text { broth) }\end{array}$ & $35.3 \pm 0.5$ & $50.3 \pm 0.5$ & $27.4 \pm 0.3$ \\
\hline Isolated (2 x CMC) & & & $45.6 \pm 0.4$ \\
\hline Isolated (CMC) & $64.5 \pm 0.1$ & $121.4 \pm 0.5$ & $57.1 \pm 0.5$ \\
\hline Isolated (1/2 CMC) & $89.0 \pm 0.3$ & $205.9 \pm 0.1$ & $64.7 \pm 0.6$
\end{tabular}

\subsubsection{Application of biosurfactant to remove hydrophobic contaminant in static and kinetic} tests.

The present study carried out static and dynamic (kinetic) tests using sand contaminated artificially with motor oil. The static test was carried out in packed glass columns, filled with sand, and washed with biosurfactant solutions (Figure 1).

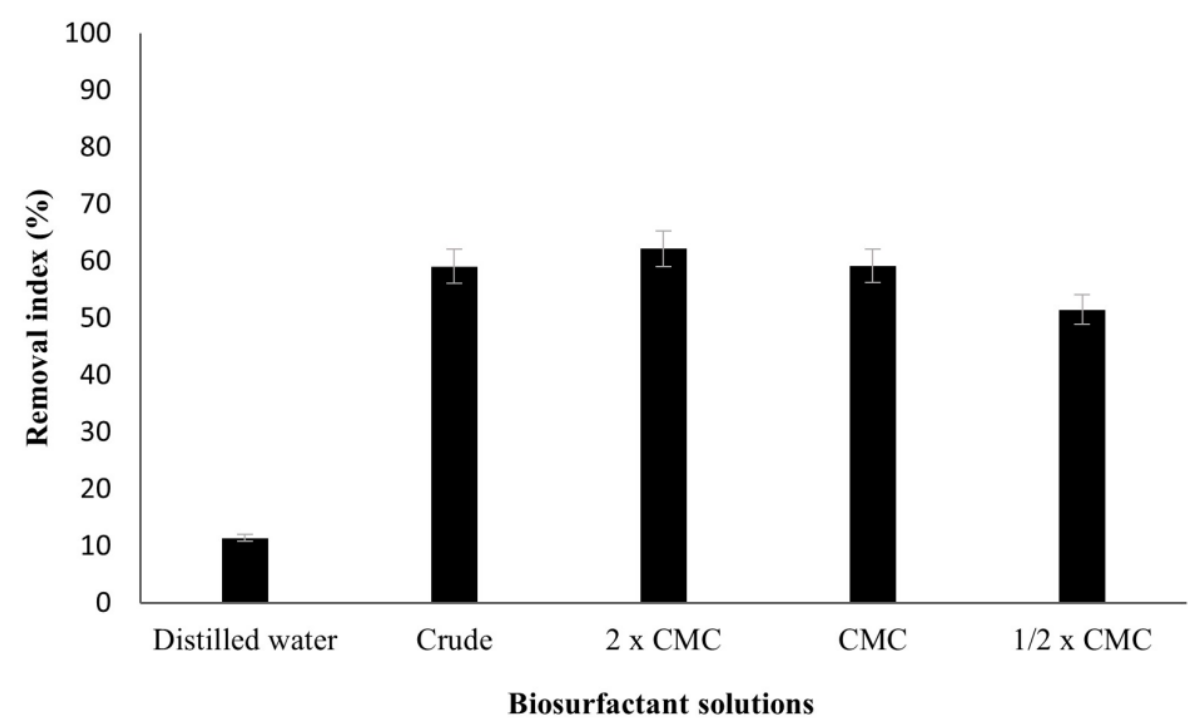

Figure 1. Removal of motor oil adsorbed to sand in packed glass columns (static assay) by the biosurfactant produced by B. cereus UCP 1615.

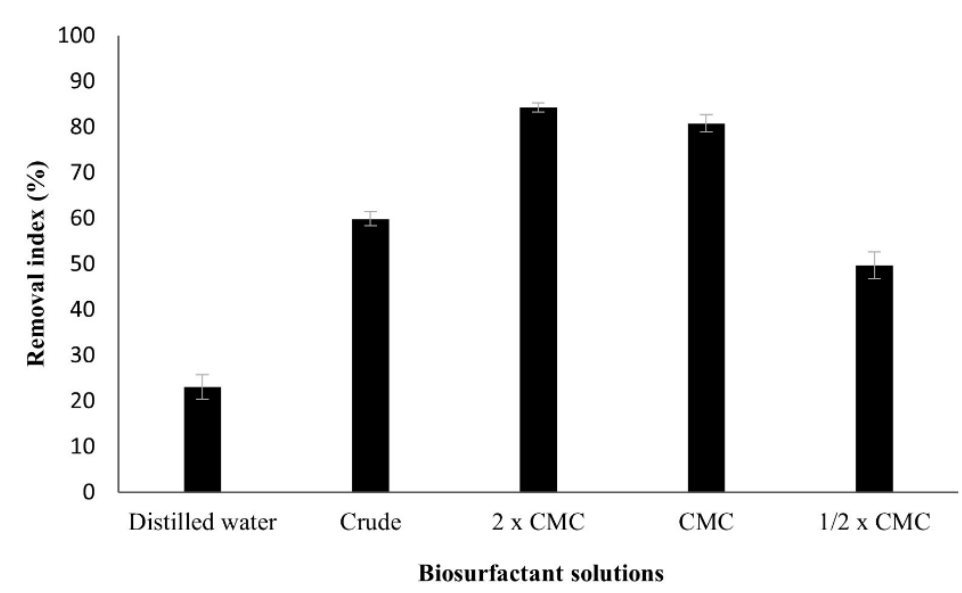

Figure 2. Removal of motor oil adsorbed to sand in flasks (kinetic assay) by the biosurfactant produced by B. cereus UCP 1615 after stirring (24h).

These test results show a $63 \pm 2.1 \%$ removal, with an $82 \%$ increase in oil removal from the sand compared to the control (water), using a concentration of twice the CMC ( $1 \mathrm{~g} / \mathrm{L})$. The rate of removal from control was $10.9 \pm 0.5 \%$. It is important to highlight the crude 
biosurfactant's efficiency (cell-free metabolic broth), with an index close to those obtained by the isolated biosurfactant solutions.

Kinetics tests for removing motor oil adsorbed on the sand were performed after 24 hours of agitation, using different concentrations of the biosurfactant from B. cereus UCP 1615. It was possible to observe an increase of up to approximately $73 \pm 2.1 \%$ in the concentration of twice the CMC, when compared with distilled water, removing $84 \pm 2.2 \%$ of the oil (Figure 2).

3.1.4. Application of biosurfactant to wash hydrophobic compound adsorbed on rocks.

Samples of rocks from the coastal environment were impregnated with motor oil and washed, without friction, with different biosurfactant concentrations from B. cereus UCP 1615. It was possible to observe removal rates of $69 \pm 2.1 \%$, approximately, at the concentration twice the CMC, that is, a 69\% increase in efficiency compared to the control (20.9\%) (Figure 3).

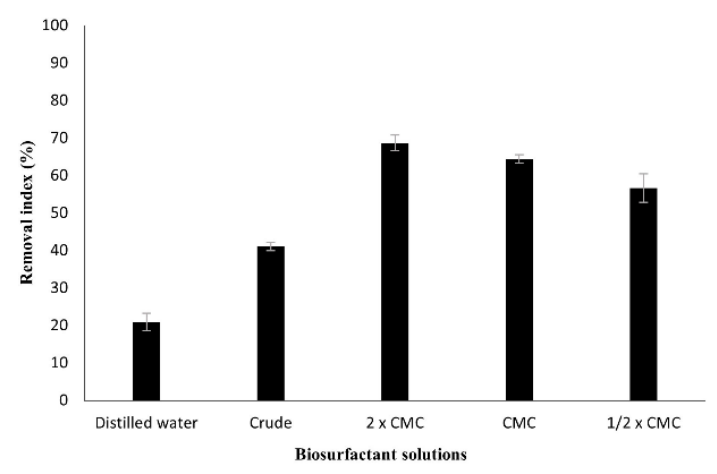

Figure 3. Removal of motor oil adsorbed to rocks by the biosurfactant produced by B. cereus UCP 1615.

\subsubsection{Formulation and conversation of the biosurfactant.}

During a period of 120 days, the crude biomolecule was subjected to conservation methods, and its surfactant properties were evaluated. Heating methods were used separately and associated with the addition of the preservative potassium sorbate.
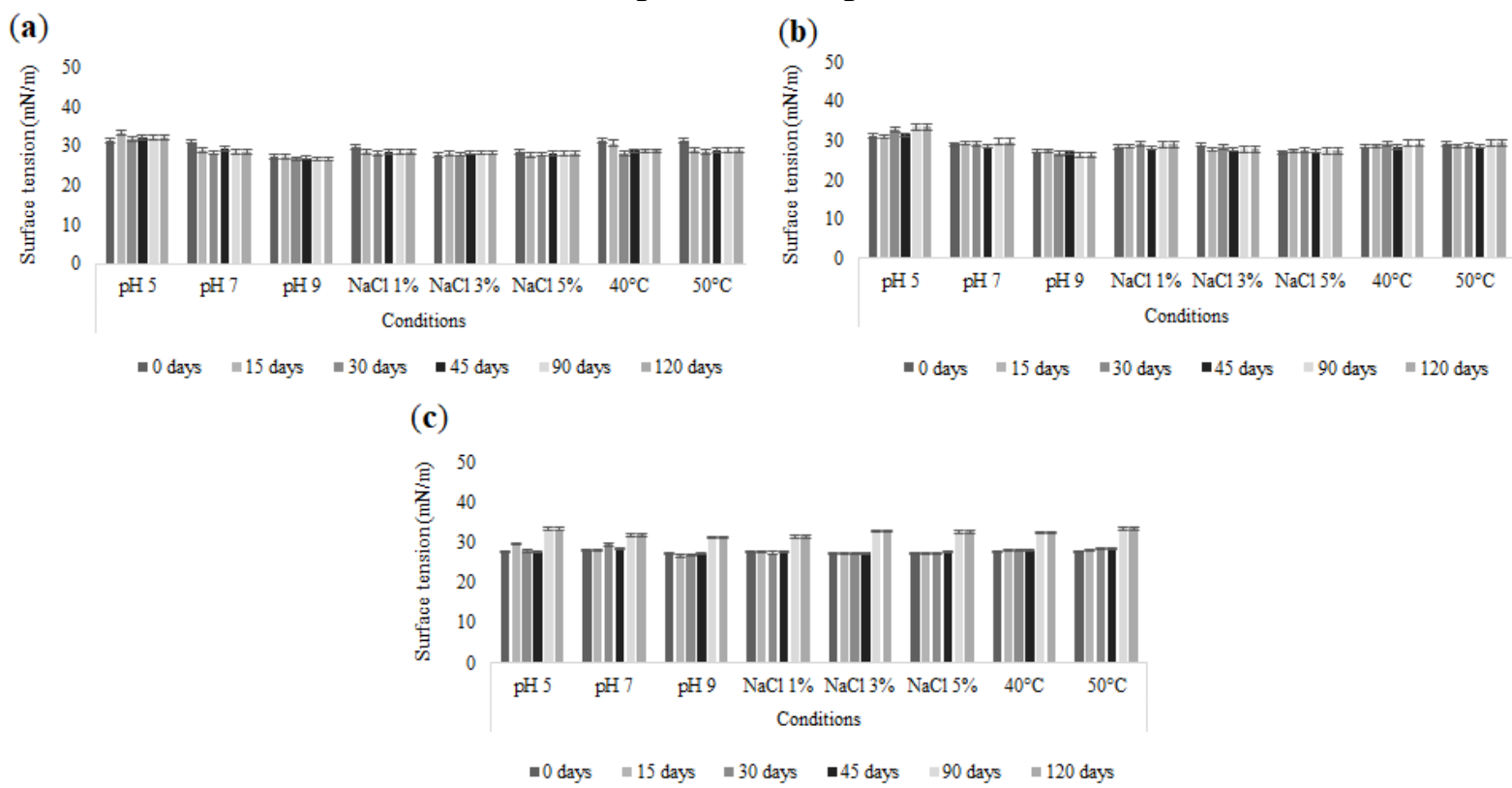

Figure 4. Surface tensions of the biosurfactant produced by B. cereus UCP 1615 over 120 days of conservation (a) with the addition of $0.2 \%$ potassium sorbate; (b) fluent vaporization with the addition of $0.2 \%$ potassium sorbate; (c) fractionated tyndallization at different $\mathrm{pH}(5,7,9), \mathrm{NaCl}$ concentration $(1,3$ and $5 \%)$ and temperature $\left(40\right.$ and $\left.50{ }^{\circ} \mathrm{C}\right)$. Error bars illustrate experimental errors (standard deviations), calculated from three independent experiments. 
The capacity to reduce the surface tension of the biosurfactant remained stable in the three conservation methods investigated and in the different conditions (Figures 4A and 4B), with the surface tension maintained around $28 \mathrm{mN} / \mathrm{m}$ over time, except in cases when the $\mathrm{pH}$ was around 5, with values close to $30 \mathrm{mN} / \mathrm{m}$.

(a)

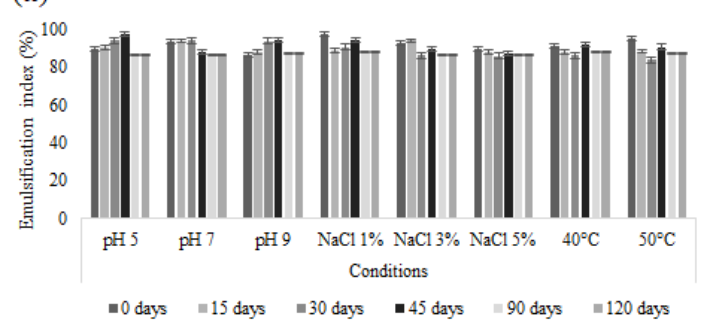

(b)

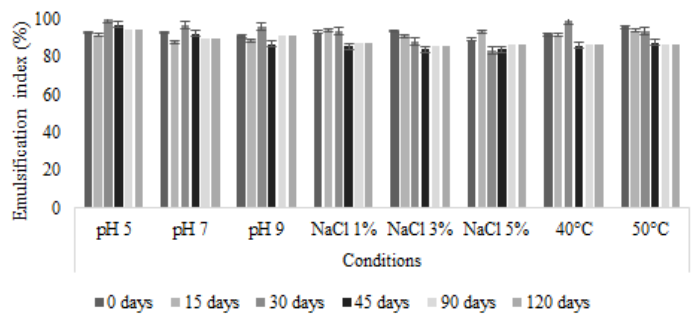

(c)

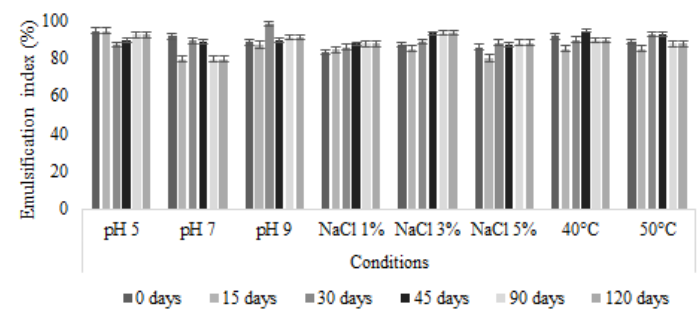

Figure 5. Motor oil emulsification indexes of the biosurfactant produced by B. cereus UCP 1615 over 120 days of conservation (a) with the addition of $0.2 \%$ potassium sorbate; (b) fluent vaporization with the addition of $0.2 \%$ potassium sorbate; (c) fractionated tyndallization at different $\mathrm{pH}(5,7,9), \mathrm{NaCl}$ concentration $(1,3$ and $5 \%$ ) and temperature $\left(40\right.$ and $\left.50{ }^{\circ} \mathrm{C}\right)$. Error bars illustrate experimental errors (standard deviations), calculated from three independent experiments.

The emulsification indexes (Figure 5) of motor oil by the biosurfactant from B. cereus UCP 1615 remained around 90 $\pm 2.1 \%$, mainly when the preservative was used in the formulation. The dispersion indexes also showed stability, with results above $75 \pm 3.0 \%$ up to the 45th day, when the preservative and the heating were associated (Figures 6A and 6B). The acidic $\mathrm{pH}$ showed the lowest values in all cases.

(a)

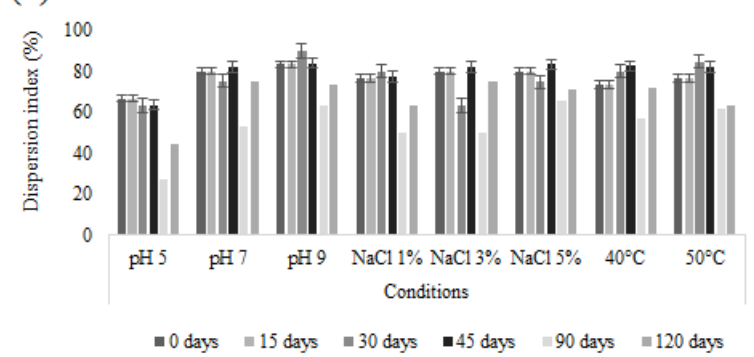

(b)

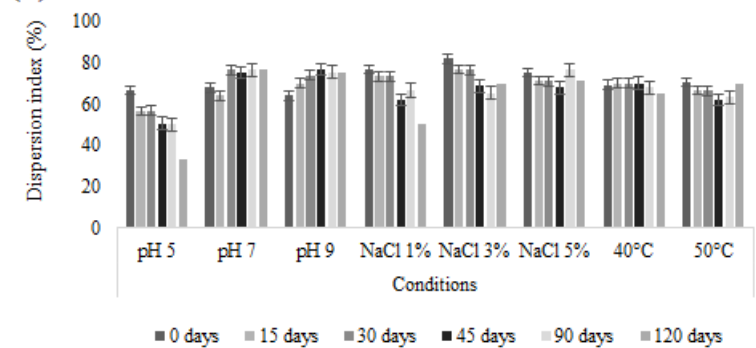

(c)

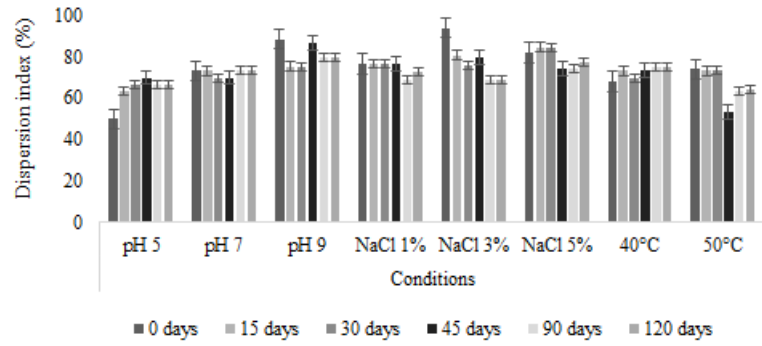

Figure 6. Motor oil dispersion by the biosurfactant from B. cereus UCP 1615 over 120 days of conservation (a) with the addition of $0.2 \%$ potassium sorbate; (b) fluent vaporization with the addition of $0.2 \%$ potassium sorbate; (c) fractionated tyndallization at different $\mathrm{pH}(5,7,9), \mathrm{NaCl}$ concentration $(1,3$ and $5 \%)$ and temperature $\left(40\right.$ and $\left.50^{\circ} \mathrm{C}\right)$. Error bars illustrate experimental errors (standard deviations) calculated from three independent experiments. 


\subsection{Discussion.}

\subsubsection{Evaluation of biosurfactant toxicity against Artemia salina.}

Artemia spp. have been widely used in research and applied in toxicology laboratories worldwide for many decades, mainly for their short life cycle, simplicity in relation to laboratory handling, and cost-effectiveness $[25,26]$. In addition to being a bioindicator in contaminated environments, it is used to test the toxicity of a wide range of chemical products and compounds, pesticides, designed nanomaterials, antibiotic drugs, antibiofilm agents, anticorrosion agents, drugs, food products, and oil dispersants [27].

The biosurfactant produced by B. cereus UCP 1615 did not prevent the hatching and life of larvae of Artemia salina, even when inserted in a medium with a concentration of twice the CMC, demonstrating that it is not toxic for this bioindicator. This result corroborates the results described by França et al. [28] and Felix et al. [29], who evaluated the toxicity of a Bacillus subtilis biosurfactant, and Santos et al. [30] using Candida lipolytica in their CMC and above this value.

\subsubsection{Evaluation of the toxicity of the biosurfactant against vegetable seeds.}

Studies show that synthetic surfactants, both anionic and non-ionic, can bind to various membrane proteins, modify their solubility and structure, and inhibit, in concentrations of $\mu$ moles, the plant's biological activity enzymes [31].

Bruin et al. [32] report that some surfactants can promote increased leakage of electrolytes, decrease chlorophyll concentration, and induce changes in the plant cell's ultrastructure. It is important to realize that, to cause any effect on seed germination and subsequent plant growth, a chemical entity must penetrate the hard and thick coating of the seeds [33].

Tiquia et al. [18] state that the germination index (GI) proves to be a very sensitive parameter because it combines the germination of seeds and the growth of seedlings (a plant embryo already developed and still closed in the seed). This test is used to assess the toxicity of the compound for different plant species. A GI value greater than $80 \%$ is considered an indication of the disappearance of toxicity.

The germination indexes (GI) obtained in this study are important to confirm this biological surfactant's biocompatibility, an advantage described in the literature in relation to synthetic surfactants. The low or absence inhibitory effect on seed germination, associated with the observation of leaf growth and the elongation of secondary roots in all conditions tested, indicates the biosurfactant's biocompatibility produced by $B$. cereus.

The GI indexes above $100 \%$ show that the biosurfactant has no toxicity and contributes to seed germination compared to the control (distilled water), with the possibility of stimulating growth in concentrations close to or below its CMC $(0.5 \mathrm{~g} / \mathrm{L})$ and being considered non-toxic.

The low IG observed when the seeds were exposed to the cell-free broth can be explained by the fact that crude extract is composed of several substances resulting from the metabolism of the microorganism, in addition to the surfactant itself; these substances can interfere with seed twinning, which justifies the low germination rates observed.

Oluwaseun et al. [34], studying the rhamnolipid from Pseudomonas aeruginosa C1501, observed that there was no inhibitory effect on the seeds (Sorghum bicolor, Solanum lycopersicum, Triticum aestivum, Vigna unguiculata, and Capsium annuum) tested, as well as 
in their root elongation; the chemical surfactant Tween 20, on the other hand, has been shown to inhibit the germination process. Rubio-Ribeaux et al. [35], evaluating the biosurfactant from Candida tropicalis UCP 1613, found that it is non-toxic to seeds of Solanum lycopersicum, Lactuca sativa L., and Brassica oleracea. This result corroborates that obtained by Santos et al. [36] for the surfactant of Streptomyces sp. DPUA1566 against Lactuca sativa L. and Brassica oleracea seeds, highlighting that germination rates were higher than $100 \%$ at the surfactant's CMC.

\subsubsection{Application of biosurfactant to remove hydrophobic contaminant in static and kinetic} tests.

Surfactants can assist in bioremediation processes since they can increase hydrocarbons' mobility and bioavailability [37]. Also, as the hydrophobic portion of the wetting agent (surfactant) bonds chemically to the hydrophobic coating on the soil particle, the soil becomes wettable. Simultaneously, the hydrophilic head attracts water molecules, allowing them to pass throughout the soil and increase infiltration [12].

The results show that the $B$. cereus biosurfactant increased the removal of oil adsorbed to the sand compared to the control condition. The rate of removal from the control, composed by distilled water, which has no chemical affinity with the oil, may be related to the gravitational action and the mechanical action of the discharge [38]. It is important to highlight the efficiency of the cell-free broth (crude biosurfactant), which showed an oil removal index close to those reached by the isolated biosurfactant solutions.

Fernandes et al. [39] evaluated the biosurfactant from B. subtilis RI4914 and observed a recovery of $40 \%$ of the oil that remained in columns filled with sand after washing with water. However, very high concentrations of the partially purified biosurfactant $(2 \mathrm{~g} / \mathrm{L})$ were required. The biosurfactant of Paenibacillus sp. D9 promoted the removal of 63\%, higher than the chemical surfactant Dodecyl sodium sulfate (SDS) [8].

Since the removal of the hydrophobic contaminant can be carried out with the association of chemical and mechanical techniques. The agitation applied to the removal process promoted an increase in the removal rates, demonstrating how the mechanical action can assist in decontamination. However, the agitation did not make the control removal index exceed the values obtained in both tests' biosurfactant presence (static and dynamic). Chaprão et al. [40] observed similar removal percentages with Bacillus sp. and Candida sphaerica. Jimoh and Lin [8] obtained the removal of $73 \%$ of the motor oil with the biosurfactant of Paenibacillus sp. D9, surpassing the chemical surfactant SDS, which removed 58\% of the oil. The biosurfactant from $P$. aeruginosa UCP0992, on the other hand, showed removal rates of around $80 \%$ when the cell-free metabolic broth was used, although the rates were below $60 \%$ when the purified biosurfactant was used [38].

\subsubsection{Application of biosurfactant to wash hydrophobic compound adsorbed on rocks.}

Coastal regions have different characteristics, from sandy to rocky regions, due to these differences in surfaces that can be affected by possible hydrophobic contaminants, which have a recalcitrant character in the environment, contaminated soil or sediments, which requires an urgent solution regarding their solubilization and biotreatment [25].

Considering the importance of these rock formations, the capacity to remove oily contaminants in rocks and stones was evaluated. The use of the biosurfactant, even at half its 
CMC, contributed to the removal of the hydrophobic contaminant attached to the rock. The highest removal values were obtained at concentrations at and twice the $\mathrm{CMC}$, rates that corroborate with those found in the literature. It is also noteworthy that the crude biosurfactant, i.e., the cell-free broth, promoted oil removal with greater efficiency than the control.

Ostendorf et al. [41], evaluating the biosurfactant from Bacillus cereus produced in a medium containing cane molasses and corn maceration liquor, observed a $60 \%$ percentage of motor oil removal with the isolated biosurfactant at the $\mathrm{CMC}$, a value that corroborates the indexes for the same concentrations obtained in the present study (around 64\%). Experiments carried out using the crude and isolated biosurfactant $(0.5 \%)$ of Pseudomonas cepacia, showed removal rates of approximately $81 \%$ and $68 \%$, respectively [21]. Comparing the present study results with those described in the literature, applying this biomolecule as a washing agent in coastal regions can be considered promising.

\subsubsection{Formulation and conversation of the biosurfactant.}

Biosurfactants are considered promising biotechnological products due to their versatility of applications. However, for industrial use, a formulation is needed that maintains long-term properties under diverse environmental and industrial conditions, such as a wide $\mathrm{pH}$ range, high salt concentrations, and high temperatures, which is important to obtain sterility in many processes [25].

The biosurfactant produced by B. cereus UCP 1615 maintained the ability to reduce surface tension, remaining stable under the three conservation methods investigated and under different conditions. In addition to the conservation of the surfactant property, thermostability is evident in conservation methods that use heat. The addition of potassium sorbate did not alter the property and aided stability until the 120th day.

The importance of the ability to emulsify and disperse hydrophobic compounds is described in various cleaning and remediation techniques [42]. Both skills were preserved at the end of the 120 days, with indices close to or equal to the initial ones, mainly with the preservative addition.

The dispersing action can contribute to the natural process of oil degradation in aquatic environments through the breakdown and consequent solubilization of oily compounds in small droplets. This property is related to both the capacity to reduce the interfacial tension and the surfactant's concentration.

According to Taira et al. [43], the lipopeptide surfactin produced by bacteria of the genus Bacillus has peptides in its structure that can take different forms depending on the medium's $\mathrm{pH}$, forming larger aggregates at basic $\mathrm{pH}$ than at neutral $\mathrm{pH}$. The morphology of the micelles of surfactin is affected by metal ions, $\mathrm{pH}$, and temperature [44].

Studies of formulation and conservation of biosurfactants for application in the environmental area are poorly described in the literature. However, existing studies previously conducted with Candida bombicola [22], Candida lipolytica [30], and Pseudomonas cepacia [45] in our laboratories indicate that the association of biosurfactants with potassium sorbate does not cause significant changes in the biomolecule's tensio-active capacity, even under different environmental conditions of $\mathrm{pH}$, temperature and salinity. It is important to highlight that the preservative potassium sorbate is already widely used by the food industry because it is a fungicide. 
Analyzing the studies described in the literature and the results obtained in this work, it is possible to affirm the potential of using the B. cereus UCP 1615 biosurfactant formulated with the preservative potassium sorbate as an efficient and stable remediation agent.

\section{Conclusions}

The biosurfactant produced by Bacillus cereus UCP1615 in a low-cost medium proved to be non-toxic for the environmental bioindicator and of reduced toxicity for vegetable seeds, indicating biocompatibility for application in the bioremediation of soils and rocks contaminated with hydrophobic compounds. Besides, the biosurfactant association with potassium sorbate proved to be efficient for the conservation of the surfactant properties in the long term.

\section{Funding}

This study was funded by the Fundação de Amparo à Ciência e Tecnologia do Estado de Pernambuco (FACEPE), the Coordenação de Aperfeiçoamento de Pessoal de Nível Superior (CAPES) - Finance Code 001, the Conselho Nacional de Desenvolvimento Científico e Tecnológico (CNPq), the Programa de Pesquisa \& Desenvolvimento da Agência Nacional de Energia Elétrica (ANEEL) and Centrais Elétricas da Paraíba (EPASA), Centrais Elétricas de Pernambuco S.A. (EPESA) and Termocabo S.A., Brazil.

\section{Acknowledgments}

The authors are grateful to the laboratories of the Centre for Sciences and Technology of the Universidade Católica de Pernambuco (UNICAP), Brazil, to the laboratories of the Instituto Avançado de Tecnologia e Inovação (IATI), Brazil, the Rede Nordeste de Biotecnologia (RENORBIO), Brazil, and the Universidade Federal Rural de Pernambuco (UFRPE), Brazil.

\section{Conflicts of Interest}

The authors declare no conflict of interest.

\section{References}

1. Oliveira, O.M.; Queiroz, A.F.S.; Cerqueira, J.R.; Soares, S.A.R.; Garcia, K.S.; Filho A.P.; Rosa, M.L.S.; Suzart, C.M.; Pinheiro, L.L.; Moreira, Í.T.A. Environmental disaster in the northeast coast of Brazil: Forensic geochemistry in the identification of the source of the oily material. Mar. Pollut. Bull. 2020, 160, 111597, https://doi.org/10.1016/j.marpolbul.2020.111597.

2. Magris, R.A.; Giarrizzo, T. Mysterious oil spill in the Atlantic Ocean threatens marine biodiversity and local people in Brazil. Mar Pollut Bull. 2020, 153, 110961, https://doi.org/10.1016/j.marpolbul.2020.110961.

3. Escobar, H. Mystery oil spill threatens marine sanctuary in Brazil. Science. 2019, 366, 672-672, https://doi.org/10.1126/science.366.6466.672.

4. Ribeiro, L.C.D.S.; Souza, K.B.; Domingues, E.P.; Magalhães, A.S. Blue water turns black: economic impact of oil spill on tourism and fishing in Brazilian Northeast. Curr. Issues Tour. 2020, 1-6, https://doi.org/10.1080/13683500.2020.1760222.

5. Karlapudi, A.P.; Venkateswarulu, T.C.; Tammineedi, J.; Kanumuri, L.; Ravuru, B.K.; Dirisala, V.; Kodali, V.P. Role of biosurfactants in bioremediation of oil pollution-a review. Petroleum. 2018, 4, 241-249, https://doi.org/10.1016/j.petlm.2018.03.007.

6. Singh, P.; Patil, Y.; Rale, V. Biosurfactant production: emerging trends and promising strategies. J. Appl. Microbiol. 2019, 126, 2-13, https://doi.org/10.1111/jam.14057.

7. Geetha, S.J.; Banat, I.M.; Joshi, S.J. Biosurfactants: Production and potential applications in microbial 
enhanced oil recovery (MEOR). Biocatal. Agric. Biotechnol. 2018, 14, 23-32, https://doi.org/10.1016/j.bcab.2018.01.010.

8. Jimoh, A.A.; Lin, J. Bioremediation of contaminated diesel and motor oil through the optimization of biosurfactant produced by Paenibacillus sp. D9 on waste canola oil. Bioremediat. J. 2020, 24, 21-40, https://doi.org/10.1080/10889868.2020.1721425.

9. Sarubbo, L.A.; Rocha, R.B.; Luna, J.M.; Rufino, R.D.; Santos, V.A.; Banat, I.M. Some aspects of heavy metals contamination remediation and role of biosurfactants. Chem. Ecol. 2015, 31, 707-723, https://doi.org/10.1080/02757540.2015.1095293.

10. Naughton, P.J.; Marchant, R.; Naughton, V.; Banat, I.M. Microbial biosurfactants: current trends and applications in agricultural and biomedical industries. J. Appl. Microbiol. 2019, 127, 12-28, https://doi.org/10.1111/jam.14243.

11. Penha, R.O.; Vandenberghe, L.P.S.; Faulds, C.; Soccol, V.T.; Soccol, C.R. Bacillus lipopeptides as powerful pest control agents for a more sustainable and healthy agriculture: recent studies and innovations. Planta 2020, 251, 1-15, https://doi.org/10.1007/s00425-020-03357-7.

12. Ogunmokun, F.A.; Liu, Z.; Wallach, R. The influence of surfactant-application method on the effectiveness of water-repellent soil remediation. Geoderma 2020, 362, https://doi.org/10.1016/j.geoderma.2019.114081.

13. Geissler, M.; Heravi, K.M.; Henkel, M.; Hausmann, R. Lipopeptide biosurfactants from bacillus species. In Biobased Surfactants, 2nd ed.; Hayes, D.G., Solaiman, D.K.Y., Ashby, R.D., Eds., Elsevier Inc: Amsterdam, Netherlands, 2019; 205-240, https://doi.org/10.1016/B978-0-12-812705-6.00006-X.

14. Sałek, K.; Euston, S.R. Sustainable microbial biosurfactants and bioemulsifiers for commercial exploitation. Process Biochem. 2019, 85,143-155, https://doi.org/10.1016/j.procbio.2019.06.027.

15. Biniarz, P.; Łukaszewicz, M.; Janek, T. Screening concepts, characterization and structural analysis of microbial-derived bioactive lipopeptides: a review. Crit. Ver. Biotechnol. 2017, 37, 393-410, https://doi.org/10.3109/07388551.2016.1163324.

16. Durval, I.J.B.; Resende, A.H.M.; Figueiredo, M.A.; Luna, J.M.; Rufin, R.D.; Sarubbo, L.A. Studies on Biosurfactants Produced using Bacillus cereus Isolated from Seawater with Biotechnological Potential for Marine Oil-Spill Bioremediation. J. Surfactants Deterg. 2018, 22, 349-363, https://doi.org/10.1002/jsde.12218.

17. Sobrinho, H.B.S.; Luna, J.M.; Rufino, R.D.; Porto, A.L.F.; Sarubbo, L.A. Assessment of toxicity of a biosurfactant from Candida sphaerica UCP 0995 cultivated with industrial residues in a bioreactor. Electron. J. Biotechnol. 2013,16, https://doi.org/10.2225/vol16-issue4-fulltext-4.

18. Tiquia, S.M.; Tam, N.F.Y.; Hodgkiss, I.J. Effects of composting on phytotoxicity of spent pig-manure sawdust litter. Environ. Pollut. 1996, 93, 249-256, https://doi.org/10.1016/S0269-7491(96)00052-8.

19. Rufino, R.D.; Luna, J.M.; Marinho, P.H.C.; Farias, C.B.B.; Ferreira, S.R.M.; Sarubbo, L.A. Removal of petroleum derivative adsorbed to soil by biosurfactant Rufisan produced by Candida lipolytica. J. Pet. Sci. Eng. 2013, 109, 117-122, https://doi.org/10.1016/j.petrol.2013.08.014.

20. Luna, J.M.; Sarubbo, L.A.; Campos-Takaki, G.M. A new Biosurfactant produced by Candida glabrata UCP 1002: Characteristics of stability and application in Oil Recovery. Brazilian Arch. Biol. Technol. 2009, 52, 785-793, https://doi.org/10.1590/S1516-89132009000400001.

21. Rocha e Silva, N.M.P.; Rufino, R.D.; Luna, J.M.; Santos, V.A.; Sarubbo, L.A. Screening of Pseudomonas species for biosurfactant production using low-cost substrates. Biocatal. Agric. Biotechnol. 2014, 3, 132-139, https://doi.org/10.1016/j.bcab.2013.09.005.

22. Freitas, B.G.; Brito, J.G.M.; Brasileiro, P.P.F.; Rufino, R.D.; Luna, J.M.; Santos, V.A.; Saubbo, L.A. Formulation of a commercial biosurfactant for application as a dispersant of petroleum and by-products spilled in oceans. Front. Microbiol. 2016, 7, 1-9, https://doi.org/10.3389\%2Ffmicb.2016.01646.

23. Cooper, D.G.; Goldenberg, B.G. Surface-active agents from two Bacillus species. Appl. Environ. Microbiol. 1987, 53, 224-229.

24. Ohno, A.; Ano, T.; Shoda, M. Production of the antifungal peptide antibiotic, iturin by Bacillus subtilis NB22 in solid state fermentation. J. Ferment. Bioeng. 1993, 75, 23-27, https://doi.org/10.1016/0922338X(93)90172-5.

25. Jimoh, A.A.; Lin, J. Biosurfactant: A new frontier for greener technology and environmental sustainability. Ecotoxicol. Environ. Saf. 2019, 184, 109607, https://doi.org/10.1016/j.ecoenv.2019.109607.

26. Persoone, G.; Wells, P. Artemia in aquatic toxicology: a review. In Artemia Research and its Application, 1st ed.; Sorgeloos; P.; Bengison, D.A, Decleir, W., Jaspers, F., Eds., Universa Press: Wetteren, Belgium, 1987; 259-275. 
27. Libralato, G.; Prato, E.; Migliore, L.; Cicero, A.M.; Manfra, L. A review of toxicity testing protocols and endpoints with Artemia spp. Ecol. Indic. 2016, 69, 35-49, https://doi.org/10.1016/j.ecolind.2016.04.017.

28. França, Í.W.L.; Lima, A.P.; Lemos, J.A.M.; Lemos, C.G.F.; Melo, V.M.M.; De Sant'ana, H.B.; Gonçalves, L.R.B. Production of a biosurfactant by Bacillus subtilis ICA56 aiming bioremediation of impacted soils. Catal. Today 2015, 255, 10-15, https://doi.org/10.1016/j.cattod.2015.01.046.

29. Felix, A.K.N.; Martins, J.J.L.; Almeida, J.G.L.; Giro, M.E.A.; Cavalcante, K.F.; Melo, V.M.M.; Pessoa, O.D.L.; Rocha, M.V.P.; Gonçalves, L.R.B.; Aguiar, R.S.S. Purification and characterization of a biosurfactant produced by Bacillus subtilis in cashew apple juice and its application in the remediation of oilcontaminated soil. Colloids Surf. B 2019, 175, 256-263, https://doi.org/10.1016/j.colsurfb.2018.11.062.

30. Santos, D.K.F.; Resende, A.H.M.; Almeida, D.G.; Silva, R.C.F.S.; Rufino, R.D.; Luna, J.M.; Banat, I.M.; Sarubbo, L.A. Candida lipolytica UCP0988 biosurfactant: Potential as a bioremediation agent and in formulating a commercial related product. Front. Microbiol. 2017, 8, 1-11, https://doi.org/10.3389/fmicb.2017.00767.

31. Gálvez, A.; López-Galindo, A.; Peña, A. Effect of different surfactants on germination and root elongation of two horticultural crops: implications for seed coating. New Zeal. J. Crop. Hortic. Sci. 2019, 47, 83-98, https://doi.org/10.1080/01140671.2018.1538051.

32. Bruin, W.; Van der Merwe, C.; Kritzinger, Q.; Bornman, R.; Korsten, L. Ultrastructural and developmental evidence of phytotoxicity on cos lettuce (Lactuca sativa) associated with nonylphenol exposure. Chemosphere 2017, 169, 428-436, https://doi.org/10.1016/j.chemosphere.2016.11.020.

33. Jain, N.; Bhargava, A.; Pareek, V.; Sayeed Akhtar, M.; Panwar, J. Does seed size and surface anatomy play role in combating phytotoxicity of nanoparticles? Ecotoxicology. 2017, 26, 238-249, https://doi.org/10.1007/s10646-017-1758-7.

34. Oluwaseun, A.C.; Kola, O.; Mishra, P.; Singh, J.R.; Singh, A.K.; Cameotra, S.S.; Oluwasesan, M.B. Characterization and optimization of a rhamnolipid from Pseudomonas aeruginosa C1501 with novel biosurfactant activities. Sustain. Chem. Pharm. 2017, 6, 26-36, https://doi.org/10.1016/j.scp.2017.07.001.

35. Rubio-Ribeaux, D.; Andrade, R.F.S.; Silva, G.S., Holanda, R.A.; Pele, M.A.; Nunes, P.; Vilar Junior, J.C.; Resende-Stoianoff, M.A.; Campos-Takaki, G.M. Promising biosurfactant produced by a new Candida tropicalis UCP 1613 strain using substrates from renewable-resources. African J. Microbiol. Res. 2017, 21, 981-991, https://doi.org/10.5897/AJMR2017.8486.

36. Santos, E.F.; Teixeira, M.F.S.; Converti, A.; Porto, A.L.F.; Sarubbo, L.A. Production of a new lipoprotein biosurfactant by Streptomyces sp. DPUA1566 isolated from lichens collected in the Brazilian Amazon using agroindustry wastes. Biocatal. Agric. Biotechnol. 2019, $17, \quad$ 142-150, https://doi.org/10.1016/j.bcab.2018.10.014.

37. Haftka, JJH; Hammer, J; Hermens, JLM. Mechanisms of Neutral and Anionic Surfactant Sorption to SolidPhase Microextraction Fibers. Environ Sci Technol. 2015, 49, 11053-11061, https://doi.org/10.1021/acs.est.5b02901.

38. Silva, E.J.; Correa, P.F.; Almeida, D.G.; Luna, J.M.; Rufino, R.D.; Sarubbo L.A. Recovery of contaminated marine environments by biosurfactant-enhanced bioremediation. Colloids Surf. B. 2018, 172, 127-135, https://doi.org/10.1016/j.colsurfb.2018.08.034.

39. Fernandes, P.L.; Rodrigues, E.M.; Paiva, F.R.; Ayupe, B.A.L.; Mcinerney, M.J.; Tótola, M.R. Biosurfactant, solvents and polymer production by Bacillus subtilis RI4914 and their application for enhanced oil recovery. Fuel 2016, 180, 551-557, https://doi.org/10.1016/j.fuel.2016.04.080.

40. Chaprão, M.J.; Ferreira, I.N.S.; Correa, P.F.; Rufino, R.D.; Luna, J.M.; Silva, E.J.; Sarubbo, L.A. Application of bacterial and yeast biosurfactants for enhanced removal and biodegradation of motor oil from contaminated sand. Electron J Biotechnol 2015, 18, 471-479, https://doi.org/10.1016/j.ejbt.2015.09.005.

41. Ostendorf, T.A.; Silva, I.A.; Converti, A.; Sarubbo, L.A. Production and formulation of a new low-cost biosurfactant to remediate oil-contaminated seawater. J. Biotechnol. 2019, 295, 71-79, https://doi.org/10.1016/j.jbiotec.2019.01.025.

42. Ivshina, I.B.; Kuyukina, M.S.; Krivoruchko, A.V.; Elkin, A.A.; Makarov, S.O.; Cunningham, C.J.; Peshkur, T.A.; Atlas, R.M.; Philp, J.C. Oil spill problems and sustainable response strategies through new technologies. Environ. Sci. Process Impacts 2015, 17, 1201-1219, https://doi.org/10.1039/c5em00070j.

43. Taira, T.; Yanagisawa, S.; Nagano, T.; Tsuji, T. Endo A. pH-induced conformational change of natural cyclic lipopeptide surfactin and the effect on protease activity. Colloids Surf. B. 2017, 156, 382-387, http://dx.doi.org/10.1016/j.colsurfb.2017.05.017.

44. Knoblich, A.; Matsumoto, M.; Ishiguro, R.; Murata, K.; Fujiyoshi, Y.; Ishigami, Y.; Osman, M. Electron 
cryo-microscopic studies on micellar shape and size of surfactin, an anionic lipopeptide. Colloids Surf. B. 1995, 5, 43-48, https://doi.org/10.1016/0927-7765(95)01207-Y.

45. Soares da Silva, R.C.F.; Almeida, D.G.; Brasileiro, P.P.F.; Rufino, R.D.; Luna, J.M.; Sarubbo, L.A. Production, formulation and cost estimation of a commercial biosurfactant. Biodegradation 2019, 30, 191201, https://doi.org/10.1007/s10532-018-9830-4. 